\title{
ALTernative Functions for Human FANCM at Telomeres
}

\author{
Beatriz Domingues-Silva, Bruno Silva and Claus M. Azzalin* \\ Instituto de Medicina Molecular João Lobo Antunes (iMM), Faculdade de Medicina da Universidade de Lisboa, Lisbon, \\ Portugal
}

The human FANCM ATPase/translocase is involved in various cellular pathways including DNA damage repair, replication fork remodeling and R-loop resolution. Recently, reports from three independent laboratories have disclosed a previously unappreciated role for FANCM in telomerase-negative human cancer cells that maintain their telomeres through the Alternative Lengthening of Telomeres (ALT) pathway. In ALT cells, FANCM limits telomeric replication stress and damage, and, in turn, ALT activity by suppressing accumulation of telomeric R-loops and by regulating the action of the BLM helicase. As a consequence, FANCM inactivation leads to exaggerated ALT activity and ultimately cell death. The studies reviewed here not only unveil a novel function for human FANCM, but also point to this enzyme as a promising target for anti-ALT cancer therapy.

Keywords: FANCM, telomeres, ALT, R-loops, TERRA, BLM helicase

OPEN ACCESS

Edited by:

Gaelle Legube

FR3743 Centre de Biologie Intégrative (CBI), France

Reviewed by:

Lee Zou,

Harvard Medical School,

United States

Kaushlendra Tripathi,

University of Alabama at Birmingham,

United States

*Correspondence:

Claus M. Azzalin

cmazzalin@medicina.ulisboa.pt

Specialty section:

This article was submitted to

Cellular Biochemistry,

a section of the journal

Frontiers in Molecular Biosciences

Received: 17 June 2019

Accepted: 26 August 2019 Published: 06 September 2019

Citation:

Domingues-Silva B, Silva B and Azzalin CM (2019) ALTernative Functions for Human FANCM at

Telomeres. Front. Mol. Biosci. 6:84. doi: 10.3389/fmolb.2019.00084

\section{FANCM}

Human FANConi anemia, complementation group M (FANCM) is a highly conserved protein with ATPase and DNA translocase activity, belonging to the Fanconi anemia (FA) core complex (Meetei et al., 2005). FA is a hereditary disorder characterized by bone marrow failure, hypersensitivity to agents inducing DNA interstrand crosslinks (ICLs), chromosomal abnormalities and, later in life, cancer. Although FANCM is part of the FA complex, FANCM mutations are not causative of FA (Singh et al., 2009; Bogliolo et al., 2018; Catucci et al., 2018). Nonetheless, some FANCM mutations are associated with higher risk for breast and ovarian carcinomas; hence, this enzyme can be considered a tumor-suppressor (Catucci et al., 2018; Nurmi et al., 2019; Schubert et al., 2019).

Seven independent domains with separable functions have been identified in FANCM so far (Figure 1): (i) the N-terminal PIP-box (aa 5-12), which interacts with proliferating cell nuclear antigen (PCNA) (Rohleder et al., 2016); (ii) the DEAD/DEAH-motif (aa 77-590), with ATPase activity (Meetei et al., 2005) (iii) the MID-motif (aa 661-800), which interacts with the Major Histone Fold 1 and 2 (MHF1/2) heterotetramer (Yan et al., 2010); (iv) the MM1-motif (aa 826-967), which interacts with FANCF within the FA core complex (Deans and West, 2009); (v) the MM2-motif (aa 1218-1251), which interacts with RecQ-Mediated genome Instability protein 1 (RMI1), a component of the so-called BTR complex together with Bloom (BLM) and Topoisomerase IIIA (TOP3A) (Deans and West, 2009; Hoadley et al., 2012); (vi) the ERCC4-motif (aa 1818-1956), which is required for FANCM heterodimerization with its obligatory partner Fanconi Anemia core complex-Associated Protein 24 (FAAP24) (Ciccia et al., 2007); and (vii) the C-terminal HhH domain (aa 1971-2030), which equips FANCM with DNA binding activity (Coulthard et al., 2013; Yang et al., 2013). FANCM also comprises the MM3 domain (aa 1502-1708; Figure 1) of still unknown function (Deans and West, 2009).

FANCM association with the FA complex promptly suggested a role in the repair of ICL lesions (Meetei et al., 2005). Indeed, when a replication fork encounters an ICL, the FANCM-FAAP24-MHF1-MHF2 complex enhances the recruitment of the FA complex through interaction between FANCM MM1 and FANCF (Deans and West, 2009). 


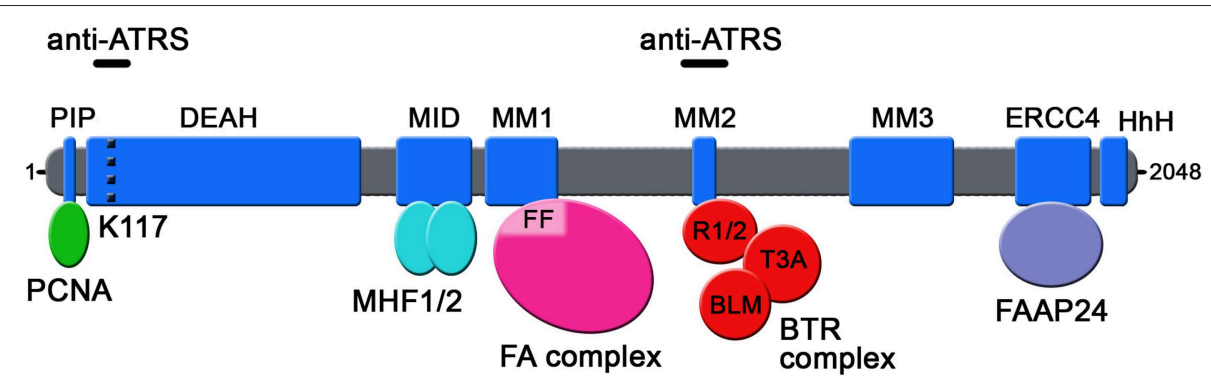

FIGURE 1 | Schematic representation of the domains so far identified in human FANCM protein. The position of lysine 117 (K117) within the ATPase pocket is indicated by a dotted black line. FF: FANCF; R1/2: RMI1 and RMI2; T3A: TOP3A; anti-ATRS: regions identified as necessary for FANCM function in suppressing ALT-associated telomeric replication stress.

This stimulates the monoubiquitination of FANCD2, another FA component, an essential event for ICL disengagement and DNA damage repair (Meetei et al., 2005; Mosedale et al., 2005; Yamamoto et al., 2011; Klein Douwel et al., 2014). However, in absence of FANCM, the FA complex still monoubiquitinates FANCD2, albeit less efficiently, and triggers repair (Bakker et al., 2009; Singh et al., 2009). This might explain why mutations in the FANCM gene are not causative of FA. FANCM also allows remodeling of arrested replication forks and traversing of ICL lesions independently of the FA complex (Huang et al., 2013). This requires FANCM ATPase activity and the interaction of the PIP-motif with PCNA (Huang et al., 2013; Rohleder et al., 2016).

FANCM promotes resolution of genome-wide spread R-loops (Schwab et al., 2015). The replication machinery might stall upon encountering R-loops and a lack of timely resolution of these structures can lead to genome instability (Crossley et al., 2019). In FANCM-deficient cells, R-loops accumulate across the genome and recombinant FANCM unwinds RNA:DNA hybrids in the presence of FAAP24 and ATP (Schwab et al., 2015). An ATPaseinactive mutant of FANCM (FANCM K117R) fails to suppress RNA:DNA hybrids both in vitro and in vivo, highlighting the importance of FANCM enzymatic activity in resolving R-loops (Schwab et al., 2015; Silva et al., 2019). FANCM involvement in R-loop metabolism appears to be evolutionarily conserved since budding yeasts deficient for the FANCM ortholog Mph1 accumulate genomic R-loops (Lafuente-Barquero et al., 2017). Notably, the FA components FANCD2, FANCA and FANCL also suppress R-loops in human and murine cells (Garcia-Rubio et al., 2015; Schwab et al., 2015). However, since FANCM ATPase activity is dispensable for FA complex function (Xue et al., 2008), FANCM and the other FA factors are likely to avert Rloops through separate mechanisms. FANCM ATPase activity also supports full activation of the ATR checkpoint cascade and common fragile site stability (Collis et al., 2008; Schwab et al., 2010; Wang et al., 2018).

FANCM interaction with RMI1 through its MM2-motif facilitates recruitment of the BTR complex to DNA lesions (Deans and West, 2009). Consistently, FANCM is required for the formation of BLM foci upon treatment with mitomycin C and camptopthecin (Deans and West, 2009). The BTR complex, also named "dissolvasome," promotes Holliday Junction branch migration and the dissolution of recombination intermediates that could lead to harmful sister chromatid exchange (SCE) events (Karow et al., 2000; Wu and Hickson, 2003). As a consequence, FANCM depletion in human cells causes SCE accumulation, a feature shared with BLM-deficient cells (Neff et al., 1999; Deans and West, 2009).

\section{ALTERNATIVE LENGTHENING OF TELOMERES}

The ends of linear eukaryotic chromosomes, the telomeres, are actively transcribed heterochromatic nucleoprotein structures comprising repetitive DNA sequences (5'-TTAGGG-3'/5'CCCTAA- $3^{\prime}$ in vertebrates), shelterin proteins and the long noncoding RNA TERRA (Azzalin and Lingner, 2015; Shay and Wright, 2019). The inability of canonical DNA polymerases to fully replicate linear DNA molecules at each round of cell division causes progressive telomere shortening, which cannot be buffered in cells lacking mechanisms of de novo synthesis of telomeric DNA (Shay and Wright, 2019). Upon extensive shortening, critically short telomeres accumulate in cells and emanate an irreversible DNA damage signal causing permanent growth arrest and eventually cell death (Harley et al., 1990; Nassour et al., 2019). To gain unlimited replicative potential, $85-90 \%$ of human cancer cells reactivate the reverse transcriptase telomerase, which utilizes an associated RNA moiety to produce telomeric DNA (Kim et al., 1994; Shay and Bacchetti, 1997). The remaining $10-15 \%$ of human cancers elongate telomeres trough homology-directed repair (HDR) pathways collectively known as Alternative Lengthening of Telomeres or ALT (Apte and Cooper, 2017). ALT can thus be considered a specialized DNA repair mechanism assuring cell immortality. ALT was first described in budding yeast survivors arising after crisis induced by telomerase inactivation (Lundblad and Blackburn, 1993). Few years later, ALT was reported in human cells (Bryan et al., 1995, 1997; Dunham et al., 2000). Human ALT cancers are generally of mesenchymal or epithelial origin, and comprise among others some osteosarcomas, liposarcomas, glioblastomas and astrocytomas. 
Besides being immortal and telomerase-negative, a number of features characterize ALT cells, including abundant extrachromosomal double-stranded (ds) or single-stranded (ss) telomeric DNA in circular or linear form (Ogino et al., 1998; Tokutake et al., 1998; Cesare and Griffith, 2004; Wang et al., 2004), and specialized nuclear bodies referred to as ALTassociated PML bodies (APBs). APBs contain ProMyelocytic Leukemia (PML), telomeric DNA, TERRA, shelterin components including TRF1 and TRF2, and DNA damage signaling and repair factors including RPA, RAD51, RAD52, BRCA1, and BLM and WRN helicases (Yeager et al., 1999; Johnson et al., 2001; Stavropoulos et al., 2002; Acharya et al., 2014; Arora et al., 2014; Pan et al., 2017). ALT cells are also characterized by elevated rates of exchange of DNA between sister telomeres (T-SCE) and increased transcription of TERRA, likely due to TERRA promoter hypomethylation (Bailey et al., 2004; Lovejoy et al., 2012; Arora et al., 2014). Finally, inactivation of one or both of the ATP-dependent chromatin remodelers Alpha-Thalassemia/mental Retardation X-linked (ATRX) and Death domain-Associated protein-6 (DAXX) are often found in ALT tumors (Heaphy et al., 2011; Lovejoy et al., 2012; Schwartzentruber et al., 2012). ATRX and DAXX form a complex that deposits the histone variant $\mathrm{H} 3.3$ at heterochromatic loci, including telomeres. Lack of ATRX and/or DAXX activity may explain the altered chromatin state of ALT telomeres, and possibly the deregulation in TERRA transcription and T-SCEs (Episkopou et al., 2014; Dyer et al., 2017). A recent report revealed that ALT telomeres are enriched in the heterochromatin mark $\mathrm{H} 3$ trimethylated at lysine 9 (H3K9me3), deposited by the histone methyltransferase SET Domain Bifurcated 1 (SETDB1). The same report proposed that $\mathrm{H} 3 \mathrm{~K} 9 \mathrm{me} 3$ stimulates $\mathrm{APB}$ formation, telomeric recombination and TERRA transcription (Gauchier et al., 2019). Further studies are thus necessary to fully understand the intricate interplay between heterochromatin deposition and ALT establishment and/or maintenance.

ALT HDR occurs through Break-Induced Replication (BIR) in the G2/M phase of the cell cycle. BIR is a conservative DNA synthesis-based repair pathway engaging at one-ended DNA double-strand breaks (DSBs) and arrested replication forks (Kramara et al., 2018). Two types of BIR, either RAD51- or RAD52-dependent, were firstly identified in ALT yeasts (Le et al., 1999; Chen et al., 2001). In human ALT cells, BIR does not require RAD51 while it depends on RAD52 and on the DNA polymerase $\delta$ accessory subunits POLD3 and POLD4, and on PCNA (Roumelioti et al., 2016; Zhang et al., 2019). ALT dependence on telomeric HDR implies that at least a subset of telomeres is maintained physiologically damaged. This sustained damage is replication-dependent, explaining the constitutive association of replication stress-associated factors, such as RPA and its phosphorylation-modified versions, with ALT telomeres (Arora et al., 2014; Pan et al., 2017). Although the triggers of this ALT-specific Telomeric Replication Stress (herein referred to as ATRS) have not been fully elucidated, a variety of hypotheses can be envisaged. Telomeres are difficult to replicate regions because of the repetitive nature of their sequence, the tight association of telomeric DNA with heterochromatin marks and telomeric proteins, and their richness in higher order structures including
T-loops, generated upon intramolecular invasion of the $3^{\prime}$ end ss tail of a telomere into its ds part, and telomeric R-loops (telRloops), formed by annealing of TERRA with the C-rich strand of the telomere (Sfeir et al., 2009; Balk et al., 2013; Pfeiffer et al., 2013; Arora et al., 2014). Additionally, G-quadruplexes may form when the G-rich telomeric strand exists in ss state, for example at the displacement loop of a T-loop or a telR-loop (Tarsounas and Tijsterman, 2013). Improper handling of any of those features could contribute to ATRS.

Because replication stress impairs cell proliferation through activation of DNA damage checkpoints, alleviators of ATRS are constantly active in ALT cells. The endoribonuclease RNaseH1 associates with ALT telomeres, where it degrades the RNA moiety of telR-loops. Short interference RNA (siRNA)-mediated depletion of RNaseH1 in ALT cells increases telR-loops, ATRS and circular telomeric molecules comprising ss C-rich DNA (C-circles), and ultimately causes rapid loss of entire telomeric tracts (Arora et al., 2014). The ATP-dependent DNA annealing helicase SWI/SNF-related, Matrix-associated, Actin-dependent Regulator of Chromatin, subfamily A-Like 1 (SMARCAL1), which restarts arrested replication forks through fork regression, is enriched at ALT telomeres, and its depletion using siRNAs augments ATRS, telomeric DNA damage and ALT features including C-circles (Cox et al., 2016). The checkpoint kinase Ataxia Telangiectasia and Rad3-Related (ATR) is also found at ALT telomeres and its inactivation using siRNAs or small molecule inhibitors increases ATRS and leads to cell death specifically in ALT cells, although this last notion has been questioned (Flynn et al., 2015; Deeg et al., 2016).

\section{FANCM AND ALT}

FANCM involvement in ALT was first reported by the Zhang laboratory in 2017 (Pan et al., 2017). The authors showed that FANCM and FAAP24 localize to telomeres in a variety of ALT cell lines. SiRNA-mediated depletion of FANCM, FAAP24, MHF1, or MHF2 induced ATRS in ALT cells, as demonstrated by the telomeric localization of phosphorylated RPA and the checkpoint kinase CHK1 (Pan et al., 2017). Single Molecule Analysis of Replicated DNA (SMARD) using telomeric DNA from FANCM-depleted ALT cells revealed diminished replication efficiencies, while replication genomewide was only minimally affected (Pan et al., 2017). Overall those data indicate that in absence of FANCM the replication machinery fails to fully replicate telomeric DNA, thus leading to ATRS. FANCM depletion was also shown to cause accumulation of BLM and BRCA1 at ALT telomeres, and simultaneous depletion of either of those factors together with FANCM partly averted ATRS (Pan et al., 2017). The authors proposed that ATRS induced by FANCM depletion promotes recruitment of BLM and BRCA1 to telomeres, where the two factors enhance end resection in order to restart arrested forks and repair telomeric DNA through HDR. Apparently consistent with this model, co-depletions of FANCM with BLM or BRCA1 were shown to be synthetically lethal, specifically in ALT cells (Pan et al., 2017). 
Two recent reports, from the Pickett laboratory and ours, have deepened our understanding of how FANCM functions at ALT telomeres. Both reports confirmed that FANCM depletion in ALT cells causes ATRS and telomeric DNA damage. Accumulation of phosphorylated RPA, ssDNA, and the DNA damage marks $\gamma \mathrm{H} 2 \mathrm{AX}$ and 53BP1 was observed at telomeres in cells depleted of FANCM using independent siRNAs (Lu et al., 2019; Silva et al., 2019). The two reports also established that FANCM suppresses ALT activity, likely as a consequence of ATRS alleviation. Augmented ALT features, including telomere clustering in large APBs, C-circle production and POLD3-mediated telomeric BIR in G2, were observed in FANCM-depleted ALT cells. Conversely, ALT features were not detected in telomerasepositive cells depleted of FANCM, indicating that FANCM inhibition does not cause ALT but rather FANCM has acquired specific telomeric functions in cells with already established ALT activity ( $\mathrm{Lu}$ et al., 2019; Silva et al., 2019). Moreover, both studies revealed that FANCM inhibition alone is extremely toxic for ALT cells, as it leads to rapid arrest of cell cycle progression in G2/M phase followed by cell death ( $\mathrm{Lu}$ et al., 2019; Silva et al., 2019). FANCM essentiality for ALT cell viability was further confirmed by interrogating publicly available catalogs of CRISPR/Cas9 gene knock-outs across cancer cell lines (Lu et al., 2019). These observations are in contrast with previous work from Pan and colleagues (Pan et al., 2017), who showed that FANCM depletion alone is not detrimental in ALT cells. It is likely that different siRNA efficiencies and experimental set ups for cell proliferation analysis account for those discrepancies.

Mechanistic insights from those two recent reports highlight the complexity of the mechanisms orchestrated by FANCM in ALT cells. We showed that telR-loops accumulate when
FANCM is depleted, and orthogonal resolution of telRloops through over-expression of RNaseH1 alleviates FANCM depletion-induced ATRS. FANCM likely restricts telR-loops directly, because FANCM can unwind telR-loops in vitro in an ATP-dependent manner and the K117R mutant fails to avert ATRS in FANCM-depleted cells (Silva et al., 2019). Moreover, we confirmed that BLM depletion alleviates ATRS in FANCM-depleted cells, and showed that combined RNaseH1 over-expression and BLM depletion fully eliminates ATRS induced by FANCM depletion (Silva et al., 2019). We thus proposed that deregulated telR-loops and BLM are the main triggers of ATRS, consequent ALT exacerbation and cell death when FANCM activity is inhibited. It remains possible that, besides R-loops resolution, other functions associated with the ATPase activity of FANCM (Collis et al., 2008; Schwab et al., 2010; Huang et al., 2013; Wang et al., 2018) could help support telomere stability and viability in ALT cells.

On the other side, the report by $\mathrm{Lu}$ and colleagues focused on the importance of the interaction between FANCM and the BTR complex. They showed that over-expression of FANCM suppresses ALT features including damaged telomeres and Ccircles. Conversely, over-expression of two mutant versions of FANCM unable to bind the BTR complex did not suppress those features (Lu et al., 2019). Consistent with our results, also the K117R mutant failed to suppress ALT, while a mutant unable to interact with the FA core complex behaved as wildtype FANCM when over-expressed (Lu et al., 2019). Altogether, this set of data confirms the importance of the enzymatic activity of FANCM in suppressing ALT, reveals the relevance of the interaction between FANCM and the BTR complex, and excludes that FANCM suppresses ALT as a member of

\section{A FANCM-proficient ALT cell}

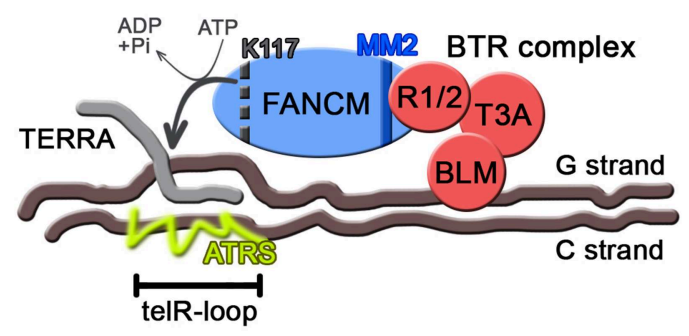

- TeIR-loop resolution

- Controlled BTR recruitment

- Controlled BLM activity

- Restricted ATRS

- Regulated ALT (telomere elongation)

- Cell proliferation

\section{B FANCM-deficient ALT cell}

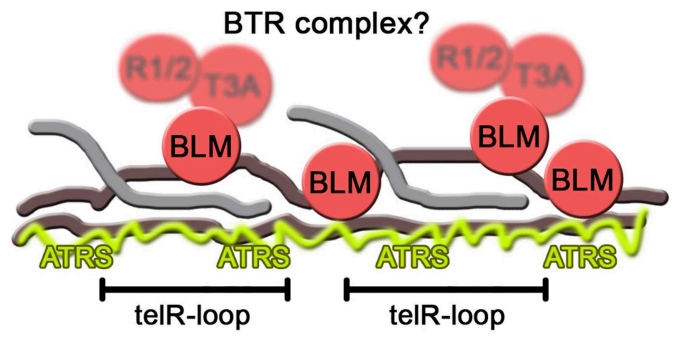

- Unresolved telR-loops

- Uncontrolled BLM (BTR?) recruitment

- Uncontrolled BLM activity

- Excessive ATRS

- Excessive ALT (telomere dysfunction)

- Cell death

FIGURE 2 | Model for FANCM function at ALT telomeres. (A) In FANCM-proficient ALT cells, FANCM association with telomeric chromatin assures unwinding of harmful telR-loops through its ATPase activity. Additionally, FANCM interaction with RMI1/2 assures regulated recruitment and activity of BLM. In this situation, ATRS is maintained below toxic levels allowing telomere elongation and infinite cell proliferation. In FANCM, lysine K117 and the MM2 motif are indicated by a dotted black line and a blue line, respectively. (B) In FANCM-deficient ALT cells, telR-loops accumulate and BLM is aberrantly recruited and activated, leading to excessive ATRS and eventually cell death. RMI1/2 and TOP3A are blurred to indicate that their recruitment to telomeres has not been tested yet in FANCM-deficient cells. 
the FA core complex. Moreover, the Pickett group utilized two independent approaches to prevent the interaction between FANCM and the BTR complex in cells: ectopic expression of a 28 aa long peptide from the MM2 sequence of FANCM or treatment with the small molecule inhibitor PIP-199. In both cases, FANCM-BTR interaction interference caused telomeric DNA damage and loss of cell viability specifically in ALT cells (Lu et al., 2019).

Collectively, the recent reports on FANCM in ALT established that FANCM is an alleviator of ATRS and unveiled two main co-players, telR-loops and BLM. TelR-loops are abundant at ALT telomeres and are kept in check by dedicated machineries including $\mathrm{RNaseH} 1$ and FANCM. Inactivation of such machineries induces telR-loop stabilization and ATRS (Arora et al., 2014; Silva et al., 2019). Although strongly suggesting that telR-loops are main triggers of ATRS, this evidence remains correlative, as systems to modulate TERRA transcription in cells are not available. It is now necessary to develop such systems and test the involvement of TERRA in telR-loop formation and ATRS. Moreover, while it is clear that RNaseH1 activity negatively regulates ATRS (Arora et al., 2014), the impact of its depletion or over-expression on the ALT mechanisms has not been fully tested. Analysis of ALT features including APBs and BIR in cells with altered RNaseH1 activity will help address this point.

As for BLM, this helicase seems to have intimate yet intricate connections with ATRS, in particular in the context of FANCM deficiency. While on one side decreasing BLM levels alleviates ATRS when FANCM is depleted (Pan et al., 2017; Silva et al., 2019), replacement of endogenous FANCM with a mutant unable to associate with the BTR complex exacerbates ATRS and ALT (Lu et al., 2019). Moreover, depletion of FANCM provokes BLM accumulation at ALT telomeres (Pan et al., 2017; Silva et al., 2019). Those apparently contradictory data can be reconciled by postulating independent activities for BLM. We propose that BLM supports regulated and productive ALT activity as long as it is properly controlled, possibly as a member of the BTR complex (Figure 2A). Consistently, depletion of any of the BTR members suppresses ALT features (Sobinoff and Pickett, 2017). Proper regulation of BLM at ALT telomeres would therefore depend on the BTR interaction with FANCM MM2 domain (Figure 2A). In the absence of this regulation, for example when FANCM is depleted or is replaced by a BTR interaction mutant, BLM could be recruited to telomeres through FANCM-independent routes and become hyperactive and therefore toxic (Figure 2B). It will be interesting to test whether RMI1 and TOP3A are also

\section{REFERENCES}

Acharya, S., Kaul, Z., Gocha, A. S., Martinez, A. R., Harris, J., Parvin, J. D., et al. (2014). Association of BLM and BRCA1 during Telomere Maintenance in ALT Cells. PLoS ONE 9:e103819. doi: 10.1371/journal.pone.01 03819

Apte, M. S., and Cooper, J. P. (2017). Life and cancer without telomerase: ALT and other strategies for making sure ends (don't) meet. Crit. Rev. Biochem. Mol. Biol. 52, 57-73. doi: 10.1080/10409238.2016.1260090 recruited to telomeres in FANCM-depleted cells and whether BLM localization at FANCM-depleted telomeres depends on the BTR complex.

Lastly, FANCM seems to be an optimal target for antiALT cancer therapies because it is a non-essential factor in normal and telomerase-positive cells. SiRNA-mediated depletion of FANCM in a large panel of non-ALT cells does not lead to cell cycle arrest or death (Lu et al., 2019; Silva et al., 2019). Telomerase-positive human colorectal carcinoma HCT116 cells, mouse embryonic fibroblasts and chicken DT40 cells knockedout for FANCM proliferate normally unless challenged with DNA damaging agents (Mosedale et al., 2005; Bakker et al., 2009; Huang et al., 2013). Individuals with FANCM mutations reach adulthood without major complications (Meetei et al., 2005; Catucci et al., 2018). Targeting FANCM, more specifically its enzymatic activity or its interaction with the BTR complex, holds the potential for a successful treatment of ALT cancers. One possible caveat comes from the observations that human FANCM mutants might develop cancer, likely telomerase-positive, late in life (Catucci et al., 2018; Nurmi et al., 2019; Schubert et al., 2019). Nevertheless, considering the fast and dramatic effects of FANCM depletion on ALT cells, we anticipate that transient FANCM inhibition should be sufficient to extirpate ALT in absence of secondary effects on patients.

\section{AUTHOR CONTRIBUTIONS}

BD-S, BS, and CA wrote, revised, and edited the manuscript.

\section{FUNDING}

Research in the Azzalin laboratory is supported by the European Molecular Biology Organization (IG3576) and the Fundação para a Ciência e a Tecnologia (IF/01269/2015; PTDC/BIAMOL/29352/2017; PTDC/MED-ONC/28282/2017). Publication costs were supported by UID/BIM/50005/2019, project funded by the Fundação para a Ciência e a Tecnologia/Ministério da Ciência, Tecnologia e Ensino Superior (MCTES) through Fundos do Orçamento de Estado.

\section{ACKNOWLEDGMENTS}

We thank Filipe Tavares-Cadete for critical reading of the manuscript and the CMAzzalin laboratory for helpful discussions. 
life of telomerase-negative cells. Nucleic Acids Res. 32, 3743-3751. doi: 10.1093/nar/gkh691

Bakker, S. T., Van De Vrugt, H. J., Rooimans, M. A., Oostra, A. B., Steltenpool, J., Delzenne-Goette, E., et al. (2009). Fancm-deficient mice reveal unique features of Fanconi anemia complementation group M. Hum. Mol. Genet. 18, 3484-3495. doi: 10.1093/hmg/ ddp297

Balk, B., Maicher, A., Dees, M., Klermund, J., Luke-Glaser, S., Bender, K., et al. (2013). Telomeric RNA-DNA hybrids affect telomere-length dynamics and senescence. Nat. Struct. Mol. Biol. 20, 1199-1205. doi: 10.1038/nsmb.2662

Bogliolo, M., Bluteau, D., Lespinasse, J., Pujol, R., Vasquez, N., D’enghien, C. D., et al. (2018). Biallelic truncating FANCM mutations cause early-onset cancer but not Fanconi anemia. Genet. Med. 20, 458-463. doi: 10.1038/gim.2017.124

Bryan, T. M., Englezou, A., Dalla-Pozza, L., Dunham, M. A., and Reddel, R. R. (1997). Evidence for an alternative mechanism for maintaining telomere length in human tumors and tumor-derived cell lines. Nat. Med. 3, 1271-1274. doi: $10.1038 / \mathrm{nm} 1197-1271$

Bryan, T. M., Englezou, A., Gupta, J., Bacchetti, S., and Reddel, R. R. (1995). Telomere elongation in immortal human cells without detectable telomerase activity. EMBO J. 14, 4240-4248. doi: 10.1002/j.1460-2075.1995.tb00098.x

Catucci, I., Osorio, A., Arver, B., Neidhardt, G., Bogliolo, M., Zanardi, F., et al. (2018). Individuals with FANCM biallelic mutations do not develop Fanconi anemia, but show risk for breast cancer, chemotherapy toxicity and may display chromosome fragility. Genet. Med. 20, 452-457. doi: 10.1038/gim.2017.123

Cesare, A. J., and Griffith, J. D. (2004). Telomeric DNA in ALT cells is characterized by free telomeric circles and heterogeneous t-loops. Mol. Cell. Biol. 24, 9948-9957. doi: 10.1128/MCB.24.22.9948-9957.2004

Chen, Q., Ijpma, A., and Greider, C. W. (2001). Two survivor pathways that allow growth in the absence of telomerase are generated by distinct telomere recombination events. Mol. Cell. Biol. 21, 1819-1827. doi: 10.1128/MCB.21.5.1819-1827.2001

Ciccia, A., Ling, C., Coulthard, R., Yan, Z., Xue, Y., Meetei, A. R., et al. (2007). Identification of FAAP24, a Fanconi anemia core complex protein that interacts with FANCM. Mol. Cell. 25, 331-343. doi: 10.1016/j.molcel.2007.01.003

Collis, S. J., Ciccia, A., Deans, A. J., Horejsi, Z., Martin, J. S., Maslen, S. L., et al. (2008). FANCM and FAAP24 function in ATR-mediated checkpoint signaling independently of the Fanconi anemia core complex. Mol. Cell. 32, 313-324. doi: 10.1016/j.molcel.2008.10.014

Coulthard, R., Deans, A. J., Swuec, P., Bowles, M., Costa, A., West, S. C., et al. (2013). Architecture and DNA recognition elements of the Fanconi anemia FANCM-FAAP24 complex. Structure 21, 1648-1658. doi: 10.1016/j.str.2013.07.006

Cox, K. E., Marechal, A., and Flynn, R. L. (2016). SMARCAL1 Resolves Replication Stress at ALT Telomeres. Cell Rep. 14, 1032-1040. doi: 10.1016/j.celrep.2016.01.011

Crossley, M. P., Bocek, M., and Cimprich, K. A. (2019). R-loops as cellular regulators and genomic threats. Mol. Cell. 73, 398-411. doi: 10.1016/j.molcel.2019.01.024

Deans, A. J., and West, S. C. (2009). FANCM connects the genome instability disorders Bloom's Syndrome and Fanconi Anemia. Mol. Cell. 36, 943-953. doi: 10.1016/j.molcel.2009.12.006

Deeg, K. I., Chung, I., Bauer, C., and Rippe, K. (2016). Cancer cells with alternative lengthening of telomeres do not display a general hypersensitivity to ATR inhibition. Front. Oncol. 6:186. doi: 10.3389/fonc.2016.00186

Dunham, M. A., Neumann, A. A., Fasching, C. L., and Reddel, R. R. (2000). Telomere maintenance by recombination in human cells. Nat. Genet. 26, 447-450. doi: 10.1038/82586

Dyer, M. A., Qadeer, Z. A., Valle-Garcia, D., and Bernstein, E. (2017). ATRX and DAXX: mechanisms and mutations. Cold Spring Harb. Perspect. Med. 7:a026567. doi: 10.1101/cshperspect.a026567

Episkopou, H., Draskovic, I., Van Beneden, A., Tilman, G., Mattiussi, M., Gobin, M., et al. (2014). Alternative Lengthening of Telomeres is characterized by reduced compaction of telomeric chromatin. Nucleic Acids Res. 42, 4391-4405. doi: $10.1093 /$ nar/gku114

Flynn, R. L., Cox, K. E., Jeitany, M., Wakimoto, H., Bryll, A. R., Ganem, N. J., et al. (2015). Alternative lengthening of telomeres renders cancer cells hypersensitive to ATR inhibitors. Science 347, 273-277. doi: 10.1126/science.1257216
Garcia-Rubio, M. L., Perez-Calero, C., Barroso, S. I., Tumini, E., HerreraMoyano, E., Rosado, I. V., et al. (2015). The fanconi anemia pathway protects genome integrity from R-loops. PLoS Genet. 11:e1005674. doi: 10.1371/journal.pgen.1005674

Gauchier, M., Kan, S., Barral, A., Sauzet, S., Agirre, E., Bonnell, E., et al. (2019). SETDB1-dependent heterochromatin stimulates alternative lengthening of telomeres. Sci. Adv. 5:eaav3673. doi: 10.1126/sciadv.aav3673

Harley, C. B., Futcher, A. B., and Greider, C. W. (1990). Telomeres shorten during ageing of human fibroblasts. Nature 345, 458-460. doi: 10.1038/345458a0

Heaphy, C. M., De Wilde, R. F., Jiao, Y., Klein, A. P., Edil, B. H., Shi, C., et al. (2011). Altered telomeres in tumors with ATRX and DAXX mutations. Science 333:425. doi: $10.1126 /$ science. 1207313

Hoadley, K. A., Xue, Y., Ling, C., Takata, M., Wang, W., and Keck, J. L. (2012). Defining the molecular interface that connects the Fanconi anemia protein FANCM to the Bloom syndrome dissolvasome. Proc. Natl. Acad. Sci. U.S.A. 109, 4437-4442. doi: 10.1073/pnas.1117279109

Huang, J., Liu, S., Bellani, M. A., Thazhathveetil, A. K., Ling, C., De Winter, J. P., et al. (2013). The DNA translocase FANCM/MHF promotes replication traverse of DNA interstrand crosslinks. Mol. Cell. 52, 434-446. doi: 10.1016/j.molcel.2013.09.021

Johnson, F. B., Marciniak, R. A., Mcvey, M., Stewart, S. A., Hahn, W. C., and Guarente, L. (2001). The Saccharomyces cerevisiae WRN homolog Sgslp participates in telomere maintenance in cells lacking telomerase. EMBO J. 20, 905-913. doi: 10.1093/emboj/20.4.905

Karow, J. K., Constantinou, A., Li, J. L., West, S. C., and Hickson, I. D. (2000). The Bloom's syndrome gene product promotes branch migration of holliday junctions. Proc. Natl. Acad. Sci. U.S.A. 97, 6504-6508. doi: $10.1073 /$ pnas.100448097

Kim, N. W., Piatyszek, M. A., Prowse, K. R., Harley, C. B., West, M. D., Ho, P. L., et al. (1994). Specific association of human telomerase activity with immortal cells and cancer. Science 266, 2011-2015. doi: 10.1126/science.7605428

Klein Douwel, D., Boonen, R. A., Long, D. T., Szypowska, A. A., Raschle, M., Walter, J. C., et al. (2014). XPF-ERCC1 acts in Unhooking DNA interstrand crosslinks in cooperation with FANCD2 and FANCP/SLX4. Mol. Cell. 54, 460-471. doi: 10.1016/j.molcel.2014.03.015

Kramara, J., Osia, B., and Malkova, A. (2018). Break-induced replication: the where, the why, and the how. Trends Genet. 34, 518-531. doi: $10.1016 /$ j.tig.2018.04.002

Lafuente-Barquero, J., Luke-Glaser, S., Graf, M., Silva, S., Gomez-Gonzalez, B., Lockhart, A., et al. (2017). The Smc5/6 complex regulates the yeast Mph1 helicase at RNA-DNA hybrid-mediated DNA damage. PLoS Genet. 13:e1007136. doi: 10.1371/journal.pgen.1007136

Le, S., Moore, J. K., Haber, J. E., and Greider, C. W. (1999). RAD50 and RAD51 define two pathways that collaborate to maintain telomeres in the absence of telomerase. Genetics. 152, 143-152.

Lovejoy, C. A., Li, W., Reisenweber, S., Thongthip, S., Bruno, J., De Lange, T., et al. (2012). Loss of ATRX, genome instability, and an altered DNA damage response are hallmarks of the alternative lengthening of telomeres pathway. PLoS Genet. 8:e1002772. doi: 10.1371/journal.pgen.1002772

Lu, R., O'rourke, J. J., Sobinoff, A. P., Allen, J.,a,.M., Nelson, C. B., et al. and Pickett, H.A. (2019). The FANCM-BLM-TOP3A-RMI complex suppresses alternative lengthening of telomeres (ALT). Nat. Commun. 10:2252. doi: 10.1038/s41467-019-10180-6

Lundblad, V., and Blackburn, E. H. (1993). An alternative pathway for yeast telomere maintenance rescues est1- senescence. Cell 73, 347-360. doi: 10.1016/0092-8674(93)90234-H

Meetei, A. R., Medhurst, A. L., Ling, C., Xue, Y., Singh, T. R., Bier, P., et al. (2005). A human ortholog of archaeal DNA repair protein Hef is defective in Fanconi anemia complementation group M. Nat. Genet. 37, 958-963. doi: $10.1038 /$ ng 1626

Mosedale, G., Niedzwiedz, W., Alpi, A., Perrina, F., Pereira-Leal, J. B., Johnson, M., et al. (2005). The vertebrate Hef ortholog is a component of the Fanconi anemia tumor-suppressor pathway. Nat. Struct. Mol. Biol. 12, 763-771. doi: $10.1038 / \mathrm{nsmb} 981$

Nassour, J., Radford, R., Correia, A., Fuste, J. M., Schoell, B., Jauch, A., et al. (2019). Autophagic cell death restricts chromosomal instability during replicative crisis. Nature 565, 659-663. doi: 10.1038/s41586-019-0885-0 
Neff, N. F., Ellis, N. A., Ye, T. Z., Noonan, J., Huang, K., Sanz, M., et al. (1999). The DNA helicase activity of BLM is necessary for the correction of the genomic instability of bloom syndrome cells. Mol. Biol. Cell. 10, 665-676. doi: $10.1091 / \mathrm{mbc} \cdot 10.3 .665$

Nurmi, A., Muranen, T. A., Pelttari, L. M., Kiiski, J. I., Heikkinen, T., Lehto, S., et al. (2019). Recurrent moderate-risk mutations in Finnish breast and ovarian cancer patients. Int. J. Cancer. doi: 10.1002/ijc.32309. [Epub ahead of print].

Ogino, H., Nakabayashi, K., Suzuki, M., Takahashi, E., Fujii, M., Suzuki, T., et al. (1998). Release of telomeric DNA from chromosomes in immortal human cells lacking telomerase activity. Biochem. Biophys. Res. Commun. 248, 223-227. doi: 10.1006/bbrc. 1998.8875

Pan, X., Drosopoulos, W. C., Sethi, L., Madireddy, A., Schildkraut, C. L., and Zhang, D. (2017). FANCM, BRCA1, and BLM cooperatively resolve the replication stress at the ALT telomeres. Proc. Natl. Acad. Sci. U.S.A. 114, E5940-E5949. doi: 10.1073/pnas.1708065114

Pfeiffer, V., Crittin, J., Grolimund, L., and Lingner, J. (2013). The THO complex component Thp2 counteracts telomeric R-loops and telomere shortening. EMBO J. 32, 2861-2871. doi: 10.1038/emboj.2013.217

Rohleder, F., Huang, J., Xue, Y., Kuper, J., Round, A., Seidman, M., et al. (2016). FANCM interacts with PCNA to promote replication traverse of DNA interstrand crosslinks. Nucleic Acids Res 44, 3219-3232. doi: 10.1093/nar/gkw037

Roumelioti, F. M., Sotiriou, S. K., Katsini, V., Chiourea, M., Halazonetis, T. D., and Gagos, S. (2016). Alternative lengthening of human telomeres is a conservative DNA replication process with features of break-induced replication. EMBO Rep. 17, 1731-1737. doi: 10.15252/embr.201643169

Schubert, S., Van Luttikhuizen, J. L., Auber, B., Schmidt, G., Hofmann, W., Penkert, J., et al. (2019). The identification of pathogenic variants in BRCA1/2 negative, high risk, hereditary breast and/or ovarian cancer patients: high frequency of FANCM pathogenic variants. Int. J. Cancer 144, 2683-2694. doi: $10.1002 /$ ijc. 31992

Schwab, R. A., Blackford, A. N., and Niedzwiedz, W. (2010). ATR activation and replication fork restart are defective in FANCM-deficient cells. EMBO J. 29, 806-818. doi: 10.1038/emboj.2009.385

Schwab, R. A., Nieminuszczy, J., Shah, F., Langton, J., Lopez Martinez, D., Liang, C. C., et al. (2015). The fanconi anemia pathway maintains genome stability by coordinating replication and transcription. Mol. Cell. 60, 351-361. doi: 10.1016/j.molcel.2015.09.012

Schwartzentruber, J., Korshunov, A., Liu, X. Y., Jones, D. T., Pfaff, E., Jacob, K., et al. (2012). Driver mutations in histone H3.3 and chromatin remodelling genes in paediatric glioblastoma. Nature 482, 226-231. doi: 10.1038/nature10833

Sfeir, A., Kosiyatrakul, S. T., Hockemeyer, D., Macrae, S. L., Karlseder, J., Schildkraut, C. L., et al. (2009). Mammalian telomeres resemble fragile sites and require TRF1 for efficient replication. Cell 138, 90-103. doi: 10.1016/j.cell.2009.06.021

Shay, J. W., and Bacchetti, S. (1997). A survey of telomerase activity in human cancer. Eur. J. Cancer 33, 787-791. doi: 10.1016/S0959-8049(97)00062-2

Shay, J. W., and Wright, W. E. (2019). Telomeres and telomerase: three decades of progress. Nat. Rev. Genet. 20, 299-309. doi: 10.1038/s41576-019-0099-1

Silva, B., Pentz, R., Figueira, A. M., Arora, R., Lee, Y. W., Hodson, C., et al. (2019). FANCM limits ALT activity by restricting telomeric replication stress induced by deregulated BLM and R-loops. Nat. Commun. 10:2253. doi: 10.1038/s41467-019-10179-Z

Singh, T. R., Bakker, S. T., Agarwal, S., Jansen, M., Grassman, E., Godthelp, B. C., et al. (2009). Impaired FANCD2 monoubiquitination and hypersensitivity to camptothecin uniquely characterize Fanconi anemia complementation group M. Blood 114, 174-180. doi: 10.1182/blood-2009-02-207811
Sobinoff, A. P., and Pickett, H. A. (2017). Alternative lengthening of telomeres: DNA repair pathways converge. Trends Genet. 33, 921-932. doi: 10.1016/j.tig.2017.09.003

Stavropoulos, D. J., Bradshaw, P. S., Li, X., Pasic, I., Truong, K., Ikura, M., et al. (2002). The Bloom syndrome helicase BLM interacts with TRF2 in ALT cells and promotes telomeric DNA synthesis. Hum. Mol. Genet. 11, 3135-3144. doi: $10.1093 / \mathrm{hmg} / 11.25 .3135$

Tarsounas, M., and Tijsterman, M. (2013). Genomes and G-quadruplexes: for better or for worse. J. Mol. Biol. 425, 4782-4789. doi: 10.1016/j.jmb.2013.09.026

Tokutake, Y., Matsumoto, T., Watanabe, T., Maeda, S., Tahara, H., Sakamoto, S., et al. (1998). Extra-chromosomal telomere repeat DNA in telomerase-negative immortalized cell lines. Biochem. Biophys. Res. Commun. 247, 765-772. doi: 10.1006/bbrc. 1998.8876

Wang, H., Li, S., Oaks, J., Ren, J., Li, L., and Wu, X. (2018). The concerted roles of FANCM and Rad52 in the protection of common fragile sites. Nat. Commun. 9:2791. doi: 10.1038/s41467-018-05066-y

Wang, R. C., Smogorzewska, A., and De Lange, T. (2004). Homologous recombination generates T-loop-sized deletions at human telomeres. Cell 119, 355-368. doi: 10.1016/j.cell.2004.10.011

Wu, L., and Hickson, I. D. (2003). The Bloom's syndrome helicase suppresses crossing over during homologous recombination. Nature 426, 870-874. doi: 10.1038/nature 02253

Xue, Y., Li, Y., Guo, R., Ling, C., and Wang, W. (2008). FANCM of the Fanconi anemia core complex is required for both monoubiquitination and DNA repair. Hum. Mol. Genet. 17, 1641-1652. doi: 10.1093/hmg/ddn054

Yamamoto, K. N., Kobayashi, S., Tsuda, M., Kurumizaka, H., Takata, M., Kono, K., et al. (2011). Involvement of SLX4 in interstrand cross-link repair is regulated by the Fanconi anemia pathway. Proc. Natl. Acad. Sci. U.S.A. 108, 6492-6496. doi: $10.1073 /$ pnas. 1018487108

Yan, Z., Delannoy, M., Ling, C., Daee, D., Osman, F., Muniandy, P. A., et al. (2010). A histone-fold complex and FANCM form a conserved DNAremodeling complex to maintain genome stability. Mol. Cell. 37, 865-878. doi: 10.1016/j.molcel.2010.01.039

Yang, H., Zhang, T., Tao, Y., Wang, F., Tong, L., and Ding, J. (2013). Structural insights into the functions of the FANCM-FAAP24 complex in DNA repair. Nucleic Acids Res. 41, 10573-10583. doi: 10.1093/nar/gkt788

Yeager, T. R., Neumann, A. A., Englezou, A., Huschtscha, L. I., Noble, J. R. and Reddel, R. R. (1999). Telomerase-negative immortalized human cells contain a novel type of promyelocytic leukemia (PML) body. Cancer Res. 59, 4175-4179.

Zhang, J. M., Yadav, T., Ouyang, J., Lan, L., and Zou, L. (2019). Alternative lengthening of telomeres through two distinct break-induced replication pathways. Cell Rep. 26, 955-968 e953. doi: 10.1016/j.celrep.2018. 12.102

Conflict of Interest Statement: The authors declare that the research was conducted in the absence of any commercial or financial relationships that could be construed as a potential conflict of interest.

Copyright (ㄷ) 2019 Domingues-Silva, Silva and Azzalin. This is an open-access article distributed under the terms of the Creative Commons Attribution License (CC BY). The use, distribution or reproduction in other forums is permitted, provided the original author(s) and the copyright owner(s) are credited and that the original publication in this journal is cited, in accordance with accepted academic practice. No use, distribution or reproduction is permitted which does not comply with these terms. 